\title{
Evaluate the Efficacy of Root Powder of Picrorhiza Scrophulariiflora Pennellon the Management of Constipation
}

\begin{abstract}
Constipation is a common gastro-intestinal disorder which an individual experiences uncomfortable or infrequent bowel movements. Picrorhiza scrophulariiflora Pennell is a common herb having many traditional claims including constipation. This study is a quasi-experimental study to determine the internal administration of Picrorhiza scrophulariiflora Pennell capsule in the management of patient with constipation.

In present study, thirty patients with constipation were selected according to the inclusive and exclusive criteria and treated with Picrorhiza scrophulariiflora Pennell capsule $650 \mathrm{mg}$ orally, two times a day. Evaluation visit were made at base line and $3^{\text {rd }}, 6^{\text {th }}, 10^{\text {th }}, 15^{\text {th }}, 20^{\text {th }}, 25^{\text {th }}, 30^{\text {th }}$ and $40^{\text {th }}$ days. The treatment was stopped when signs and symptoms completely disappeared but patients were observed and monitored until $40^{\text {th }}$ day.

Results showed statistically highly significant improvement on parameters like hard stool, incomplete evacuation, Excessive straining, Lower abdomen fullness and Gas collection $(p<0.000)$. It was observed that there was a significant reduction in all symptoms in end of the study. In general it is hoped that the findings of this study would help in the global use of Picrorhiza scrophulariiflora for the treatment of Constipation.
\end{abstract}

Keywords: Constipation; Picrorhiza scrophulariiflora pennell; Constipation; Malakkattu

Research Artic
Volume 9 Issue 1 - 2017
Navaretnam Kohilatharshini ${ }^{1}$, Vijitha
Paheerathan ${ }^{2 *}$ and Piratheepkumar $\mathbf{R}^{2}$
${ }^{1}$ Intern medical officer, Sri Lanka
${ }^{2}$ Eastern University, Sri Lanka

*Corresponding author: Vijitha Paheerathan, Eastern University, Sri Lanka, Email: geethan1978@live.com

Received: March 06, 2017 | Published: October 24, 2017

\section{Introduction}

\section{Study}

This study is a quasi-experimental study to determine the internal administration of Picrorhiza scrophulariiflora Pennell capsule in the management of patient with Constipation. Siddha medicine is being used largely about decades for the treatment of Constipation. Plants are the only economic source of a number of well-established and important drugs. In addition, they are also the source of chemical intermediates needs for the production of some drugs [1]. If treatment with plants are not effective gradual use of metals and minerals are suggested for choice of treatment $[2]$.

\section{"Ntu;ghU jioghU kpQ;rpdf; fhy; \\ nky;y nky;y gw;g nre;j\}uk; ghU"}

Picrorhiza scrophulariflora Pennell is a common herb has been widely used as an indigenous medicine for the treatment Indigestion, Fever, Eczema, Wound, Vazhi noikal., and Constipation for many years [2] However, the laxative property of Picrorhiza scrophulariiflora Pennell has not been proved scientifically. Current situation expect scientific explanation for all. Therefore this clinical study was focused on to provide a detail account of constipation and determine the internal administration of Picrorhiza scrophulariiflora Pennell capsule in the management of patient with constipation.

\section{Background and justification of the study \\ 'khe;jQ; Ruikak; thAfug; ghdhkQ; \\ NrHe;jkyf; fl;L jpupNjhlk; - Nghe;jnghl;Lg; \\ Gz;tapW NehapitNghk; nghw;nfhbNa - NgjpAz;lhk; \\ jpz;fLF Nuhfzpf;Fj; N;jH' (m.F)}

According to the above quotation which is mentioned in the kunapadam part-1, the powder of Picrorhiza scrophulariiflora Pennell cured many diseases [2]. Many researches were done related to Constipation, but no study was done on Picrorhiza scrophulariiflora Pennell on Constipation. The extracts of Picrorhiza scrophulariiflora Pennell possess a wide range of pharmacological activities including anti-inflammatory, antidiabetic, immunomodulatroy activities [2]. But laxative action still not proved scientifically. Therefore this study deals with laxative property of root of Picrorhiza scrophulariiflora Pennell on constipation. 


\section{Objectives}

To determine the effectiveness of Picrorhiza scrophulariiflora Pennell as an internal administration for constipation.

\section{Methodology}

This is a quasi-experimental study in this study, Constipation patients, according to the inclusive criteria and exclusive criteria were selected at the Rural Ayurveda Hospital, Kopalapuram. The selected patients treated with selected drug. This chapter deals with the study area, study design, Study unit, selection of patients, Inclusion criteria, Exclusion criteria, ethical clearance, Preparation of medicine, Instrument, Data collection, Treatment, Adverse effects or side effects, Clinical assessment, Instrument, Explanation of the selected variables in the Questionnaires, Data analysis.

\section{Study design}

It is a quasi-experimental study. Constipation patients according to the inclusive criteria were selected at the Rural Ayurveda Hospital, Kopalapuram. All the selected patients were interviewed by the researcher on their first visit to the OPD. They were assured that all information obtained from them would be strictly confidential. The purpose of the trial was explained to the patients and those who volunteered signed in the 'informed consent' form to enrol in the trial. Drugs were administrated with eight intervention treatment arms. The treatment was stopped when signs and symptoms disappeared but patient were observed and monitored until $40^{\text {th }}$ day.

\section{Study unit}

30 patients were selected for this study. Patients were selected based on randomization schedule.

\section{Selection of patients}

Thirty Patients of between 20 to 30 years of age, both sexes presenting with the signs and symptoms of constipation were selected randomly based on randomization schedule from Out patients Department of the Rural Ayurveda Hospital, Kopalapurm, Trincomalee. They were assured that all information obtained from them would be strictly confidential. These patients were subjected to a detailed clinical examination based on proforma specially prepared for this study. Diagnosis was made on the basis of the history and physical examination. The following physical examination was made by the researcher with the under supervision of M.O.I.C, Rural Ayurveda Hospital, Kopalapurm;

a. Addavitha paridchai (villi, molli, navu, naddi, malam, siruner, sparisam, niram)

b. General examination.

c. In systemic examination special emphasis was given to the Gastro intestinal System. In addition to this Cardiovascular System and Respiratory System were also examined by the researcher.

\section{Inclusion criteria}

a. Age- patients were selected between age group of 20-30 year. b. Both Sex.

c. Sign \& symptoms of constipation based on history taking.

i. Include two or three of the following

a. Hard stool.

b. Excessive straining.

c. Incomplete evacuation.

d. Lower abdomen fullness.

e. Gas collection.

Those who give the consent

\section{Exclusion criteria}

a. Below 20 years.

b. Above the 30 years.

c. Patients who used any drug for various diseases.

d. Individuals suffering from any other systemic disease Diabetes, Hypertension, Rectal Prolapse, Anal stenosis, Analfissure, Piles, Rectocele.

\section{Ethical clearance}

Ethical clearance was obtained from Ethical Review Committee of Institute of Indigenous Medicine, university of Colombo.

\section{Preparation of medicine}

Collection of plant: The dry herb of Picrorhiza scrophulariiflora Pennell was collected from the Thirunellveli, Jaffna district in the month of July.

Authentication of plant: The dry herb of Picrorhiza scrophulariiflora Pennell was taxonomically authenticated by Kunapadam division, Unit of Siddha Medicine, Trincomalee Campus, EUSL.

Purification of plant: The dry herb of Picrorhiza scrophulariiflora Pennell cleaned and washed with water and dried in shade. Then cut in to small pieces then boiled in cow's milk and allowed to dry in shade for 3 days.

Preparation of capsule: The dry herb of Picrorhiza scrophulariiflora Pennell was dried out under the shade then bruised, well strained through fine meshes of sieve. This powder was filled in a capsule by using manual capsule filling machine and prepared the capsules and stored in dry and air tight glass bottle for further studies.

\section{Data collection}

According to inclusive criteria patient were selected at Konesapuri area during July 15 to September 15, 2016. The purpose of trial was explained to the patient to get their consent a selected patient was interviewed by the researcher on their first visit to the OPD. The patient were subjected to a detailed clinical examination based on proforma specially prepared this study. Diagnosis will be made on the basis of history and clinical examination. 


\section{Treatment}

All the selected patients will be treated with $650 \mathrm{mg}$ of root powder of Picrorhiza scrophulariiflora Pennell capsule orally, twice a day. The treatment was stopped when signs and symptoms completely disappeared but patient were observed and monitored until $40^{\text {th }}$ day.

\section{Side effects}

Side effects were observed after the treatment by the researcher.

\section{Clinical assessment}

Considering the symptoms of constipation as given in modern science the assessments were made. Full detailed history and physical examination of the patients were recorded into specially prepared proforma for Constipation (Malakattu). Diagnosis was made on the basis of history and basic physical examination evaluation visit were made at base line and $3^{\text {rd }}, 6^{\text {th }}, 10^{\text {th }}, 15^{\text {th }}$, $20^{\text {th }}, 25^{\text {th }}, 30^{\text {th }}$ and $40^{\text {th }}$ days. The treatment was stopped when signs and symptoms disappeared but patient were observed and monitored until $40^{\text {th }}$ day.

Effectiveness of treatment was evaluated on the basis of change in the sign and symptoms of constipation. Hard stool, Excessive straining, Incomplete evacuation, Lower abdomen fullness, Gas Collection were considered as a primary efficacy variables and they were analysed by score as different between the first day of the treatment and after the treatment.

\section{Instrument}

The instrument used in this study is an interviewer (researcher) administrated questionnaire. In addition to responses to specific questions, notes were made on information obtained by examination and investigations. The follow-up of the patients were recorded at $3^{\text {th }}, 6^{\text {th }}, 10^{\text {th }}, 15^{\text {th }}, 20^{\text {th }}, 25^{\text {th }}, 30^{\text {th }}$ and $40^{\text {th }}$ days. These questions were prepared based on specific objectives.

\section{Data analysis}

The data were analysed using the Statistical Package for Social
Sciences (SPSS) version 20. Dependent variables and independent variables are used to Evaluate the effectiveness of Picrorhiza scrophulariiflora Pennell on the management of constipation of each variable is separately analysed. Following statistical techniques were used to analysis the study.

Descriptive statistics/Univariate analysis: Descriptive statistics/ univariate analysis (such as mean, frequencies and percentages) of data were performed to identify the main characteristics of the research variables.

\section{Paired-Samples T test}

a. The paired-samples: $T$ Test procedure compares the means of two variables. The procedure computes the differences between values of the two variables for each case and tests whether the average differs from 0 .

b. Confidence interval: By default, a 95\% confidence interval for the difference in means is displayed. Enter a value between 1 and 99 to request a different confidence level.

c. Missing values: When test several variables and data are missing for one or more variables, can tell the procedure which cases to include (or exclude):

a. Exclude cases analysis by analysis. Each t test uses all cases that have valid data for the tested pair of variables. Sample sizes may vary from test to test.

b. Exclude cases list wise. Each $t$ test uses only cases that have valid data for all pairs of tested variables. The sample size is constant across tests.

\section{Results and Discussion}

\section{Effect of therapy on hard stool}

$100 \%$ of selected patients were show hard stool. Initial mean value of hard stool was 2.27 and $15^{\text {th }}$ day it reduced into 0 , it means hard stool never occur following to $15^{\text {th }}$ day of treatment and also statistically highly significant result with 'p' value 0.000 in hard stool was observed (Table 1). It clearly denoted that the medicine was effective on hard stool.

Table 1: Effect of therapy on hard stool.

\begin{tabular}{|c|c|c|c|c|c|}
\hline Days & Mean & Std. Deviation & Std. Error Mean & Paired " $\mathrm{t}$ " & $\mathbf{P}$ \\
\hline Before Treatment & 2.27 & 0.740 & 0.135 & - & - \\
\hline $3^{\text {rd day }}$ & 1.57 & 0.504 & 0.092 & 8.226 & 0.000 \\
\hline $6^{\text {th }}$ day & 1.30 & 0.535 & 0.098 & 9.522 & 0.000 \\
\hline $10^{\text {th }}$ day & 0.33 & 0.479 & 0.088 & 18.154 & 0.000 \\
\hline $15^{\text {th }}$ day & 0.00 & 0.000 & 0.000 & 16.784 & 0.000 \\
\hline $20^{\text {th }}$ day & 0.00 & 0.000 & 0.000 & 16.784 & 0.000 \\
\hline $25^{\text {th }}$ day & 0.00 & 0.000 & 0.000 & 16.784 & 0.000 \\
\hline $30^{\text {th }}$ day & 0.00 & 0.000 & 0.000 & 16.784 & 0.000 \\
\hline $40^{\text {th }}$ day & 0.00 & 0.000 & 0.000 & 16.784 & 0.000 \\
\hline
\end{tabular}

\section{Effect of therapy on excessive straining}

$83.33 \%$ of selected patients were show Excessive staining. Initial mean value of Excessive staining was 2.47 and 15th day it reduced into 0, it means Excessive staining never occur following to $15^{\text {th }}$ day treatment. The study showed that statistically highly significant result with 'p' value 0.000 (Table 2). It clearly denoted that the medicine was effective on Excessive staining. 
Table 2: Effect of therapy on excessive straining.

\begin{tabular}{|c|c|c|c|c|}
\hline Days & Mean & Std. Deviation & Std. Error Mean & Paired “t” \\
\hline Before Treatment & 2.47 & 0.507 & 0.093 & - \\
\hline $3^{\text {rd }}$ day & 1.67 & 0.479 & 0.088 & 10.770 \\
\hline $6^{\text {th }}$ day & 0.80 & 0.484 & 0.088 & 19.039 \\
\hline $10^{\text {th }}$ day & 0.30 & 0.466 & 0.085 & 18.322 \\
\hline $15^{\text {th }}$ day & 0.00 & 0.000 & 0.000 & 26.626 \\
\hline $20^{\text {th }}$ day & 0.00 & 0.000 & 0.000 & 26.626 \\
\hline $25^{\text {th }}$ day & 0.00 & 0.000 & 0.000 & 26.626 \\
\hline $30^{\text {th }}$ day & 0.00 & 0.000 & 0.000 & 0.0000 \\
\hline $40^{\text {th }}$ day & 0.00 & 0.000 & 0.000 & 26.626 \\
\hline
\end{tabular}

\section{Effect of therapy on incomplete evacuation}

$100 \%$ of selected patients were show incomplete evacuation. Clinical study showed that Initial mean value of incomplete evacuation was 2.47 and $15^{\text {th }}$ day it reduced into 0 , it means Table 3: Effect of therapy on incomplete evacuation. incomplete evacuation never occur following to 15th day treatment and also statistically highly significant result with ' $\mathrm{p}$ ' value 0.000 (Table 3 ). It clearly denoted that the medicine was effective on incomplete evacuation.

\begin{tabular}{|c|c|c|c|c|c|}
\hline Days & Mean & Std. Deviation & Std. Error Mean & Paired “t” & P \\
\hline Before Treatment & 2.47 & 0.507 & 0.093 & - & - \\
\hline $3^{\text {rd }}$ day & 1.53 & 0.507 & 0.093 & 20.149 & 0.000 \\
\hline $6^{\text {th }}$ day & 0.97 & 0.320 & 0.058 & 16.155 & 0.000 \\
\hline $10^{\text {th }}$ day & 0.23 & 0.430 & 0.079 & 19.539 & 0.000 \\
\hline $15^{\text {th }}$ day & 0.00 & 0.000 & 0.000 & 26.626 & 0.000 \\
\hline $20^{\text {th }}$ day & 0.00 & 0.000 & 0.000 & 26.526 & 0.000 \\
\hline $25^{\text {th }}$ day & 0.00 & 0.000 & 0.000 & 26.526 & 0.000 \\
\hline $30^{\text {th }}$ day & 0.00 & 0.000 & 0.000 & 26.526 & 0.000 \\
\hline $40^{\text {th }}$ day & 0.00 & 0.000 & 0.000 & 26.526 & 0.000 \\
\hline
\end{tabular}

\section{Effect of therapy on Lower abdomen fullness}

$73.33 \%$ of selected patients were show Lower abdomen fullness. Initial mean value of Lower abdomen fullness was 2.30 and end of $15^{\text {th }}$ day it reduced into 0 , it means Lower abdomen Table 4: Effect of therapy on Lower abdomen fullness. fullness never occur following to15th day treatment. ' $\mathrm{P}$ ' value is 0.000 therefore statistically significant improvements were observed (Table 4). It clearly denoted that the medicine was effective on Lower abdomen fullness.

\begin{tabular}{|c|c|c|c|c|c|}
\hline Days & Mean & Std. Deviation & Std. Error Mean & Paired “t” & p \\
\hline Before Treatment & 2.30 & 0.702 & 0.128 & - & - \\
\hline $3^{\text {rd }}$ day & 1.63 & 0.490 & 0.089 & 7.616 & 0.000 \\
\hline $6^{\text {th }}$ day & 0.93 & 0.450 & 0.082 & 13.462 & 0.000 \\
\hline $10^{\text {th }}$ day & 0.33 & 0.479 & 0.088 & 14.083 & 0.000 \\
\hline $15^{\text {th }}$ day & 0.00 & 0.000 & 0.000 & 17.940 & 0.000 \\
\hline $20^{\text {th }}$ day & 0.00 & 0.000 & 0.000 & 17.940 & 0.000 \\
\hline $25^{\text {th }}$ day & 0.00 & 0.000 & 0.000 & 17.940 & 0.000 \\
\hline $30^{\text {th }}$ day & 0.00 & 0.000 & 0.000 & 17.940 & 0.000 \\
\hline $40^{\text {th }}$ day & 0.00 & 0.000 & 0.000 & 17.940 & 0.000 \\
\hline
\end{tabular}




\section{Effect of therapy on Gas collection}

$100 \%$ of selected patients were show Gas collection. Initial mean value of Gas collection was 2.50 and 20th day it completely

Table 5: Effect of therapy on Gas collection. reduced into 0, it means Gas collection never occur following to $20^{\text {th }}$ day of treatment. The study showed that statistically highly significant result with ' $p$ ' value 0.000 (Table 5). It clearly denoted that the medicine was effective on Gas collection.

\begin{tabular}{|c|c|c|c|c|c|}
\hline Days & Mean & Std. Deviation & Std. Error Mean & Paired “t" & P \\
\hline Before Treatment & 2.50 & 0.630 & 0.115 & - & - \\
\hline $3^{\text {rd }}$ day & 1.83 & 0.379 & 0.069 & 7.616 & 0.000 \\
\hline $6^{\text {th }}$ day & 1.33 & 0.479 & 0.088 & 9.866 & 0.000 \\
\hline $10^{\text {th }}$ day & 0.77 & 0.430 & 0.079 & 13.730 & 0.000 \\
\hline $15^{\text {th }}$ day & 0.27 & 0.450 & 0.082 & 16.804 & 0.000 \\
\hline $20^{\text {th }}$ day & 0.00 & 0.000 & 0.000 & 21.745 & 0.000 \\
\hline $25^{\text {th }}$ day & 0.00 & 0.000 & 0.000 & 21.745 & 0.000 \\
\hline $30^{\text {th }}$ day & 0.00 & 0.000 & 0.000 & 21.745 & 0.000 \\
\hline $40^{\text {th }}$ day & 0.00 & 0.000 & 0.000 & 21.745 & 0.000 \\
\hline
\end{tabular}

\section{Overall effect of improvement}

Figure 6 shows comparative overall effect on the management of constipation. The results were highly significant in symptoms. Hard stool, Excessive staining, incomplete evacuation, Lower abdomen fullness and Gas collection were considered for comparing the overall results. Initial Comparative Mean value was 2.40 , comparative mean after treatment $1.65,1.07,0.39$ and 0.05 on $3^{\text {rd }}$ day, $6^{\text {th }}$ day, $10^{\text {th }}$ day and $15^{\text {th }}$ day respectively and $20^{\text {th }}$ day it completely reduced into 0.00 , it means Constipation never occur following 20th day of treatment (Table 6).

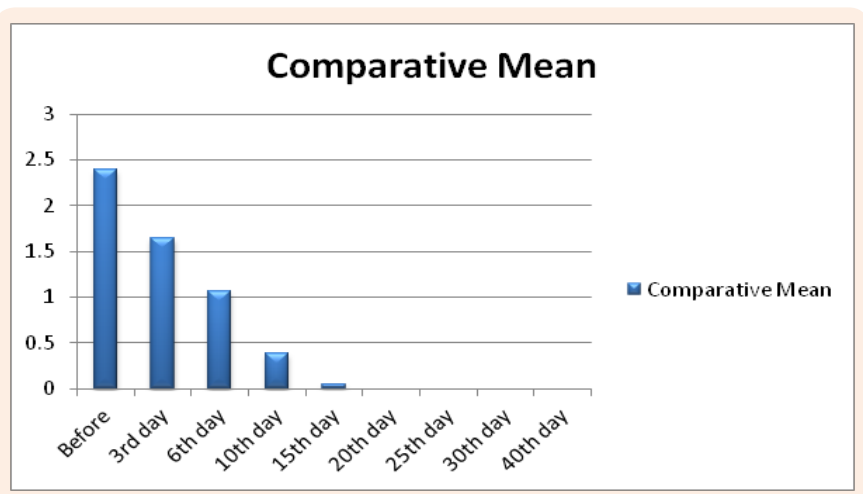

Figure 1: Overall effect of improvement.

Effectiveness is explained on the basis of taste, potency and result and action and properties of selected plant. According to Siddha, dietary and lifestyle reasons may initially lead to derangement of Vatha or Pitha causing indigestion, bloated abdomen, gassiness etc. to treat constipation, drugs acting on both Vátha and Pitha should be selected [3].

The plant Picrorhiza scrophulariflora Pennell has bitter and pungent taste, hot potency and pungent resultant. Bitter taste has Combination of air and space elements and pungent taste has Combination of air and fire elements.so prominent five elements in this plant is air element. Air element has denselessness, dryness, easiness, and inhalation properties. And also bitter taste reduces the body heat and improve bowel functions, pungent taste get rid of the distended abdomen due to indigestion. Therefore it is mildly laxative by nature [4].

The plant is hot potency, it increased the Pitha which increases the Dhatuvagni (cell metabolism) as result indigestion will be set off. So it helps to digest the food particles and the plant is pungent resultant which helps in pacification of aggravated Vátha [4].

Above explanations has been supported by the results obtained from this study.

\section{Conclusion}

Picrorhiza scrophulariiflora Pennell can be used as an effective internal administration for constipation and no strict side effect was detected. Statistically highly significant ( $p$ value 0.000 ) improvements in parameters like hard stool, excessive straining, incomplete evacuation, lower abdominal fullness and gas collection, the improvement remained same after the follow up period.

All 30 patients got relief from the symptoms on 20th day onwards, therefore the plant Picrorhiza scrophulariiflora Pennell can be recommended for constipation $650 \mathrm{mg}$ capsule two times a day for 20 days.Gunapadam porudpanpunool Moolikai Thokupu part 1 written by Murukesa muthaliyar mentioned Picrorhiza scrophulariiflora Pennell has an action to relived constipation. This was scientifically proved by this study.

\section{Suggestions and Recommendation}

Evaluate the effectiveness of Picrorhiza scrophulariiflora Pennell on the management of constipation since it is a under graduate research procedure, therefore the future research can be consider with large number of patients. 


\section{References}

1. Agrawal SS, Paridhavi M (2007) Herbal Drugs Technology, Universities Press (India) Private Limited, India, p. 1-2.

2. Murugesamuthaliyar KS (2008) Kunapadam textbook (Muthalpaakam- porutpanpunool), India Maruthuvam, Homiopathithurai, India, pp. 227.
3. Shanmugavelu M (2003) Noi Nadal Noi Muthal Nadal Thirattu part-2. Indian medicine, Homeopathy, India, pp. 150.

4. Uthamaroyan, CS (2005) A Compedium of Docrine, Government of Tamilnadu. Department of Indian and Homoeopathy. Chennai-106, India, pp. 362. 